\title{
Comparison of Blood Loss between Neutral Drainage with Tranexamic Acid and Negative Pressure Drainage without Tranexamic Acid Following Primary Total Knee Arthroplasty
}

\author{
Dong Hwi Kim, MD, Gwang Chul Lee, MD, Sang Hong Lee, MD, Chi-Hyoung Pak, MD, Sang Ha Park, MD, \\ and Sung Jung, MD \\ Department of Orthopaedic Surgery, Chosun University Hospital, Gwangju, Korea
}

\begin{abstract}
Purpose: There are many methods to reduce massive bleeding during total knee arthroplasty (TKA). In our study, tranexamic acid and neutral drainage were used to decrease total blood loss.

Materials and Methods: The study was performed on 97 TKA patients from March 2012 to January 2013. In the study group, tranexamic acid was administered and neutral drainage was applied. The study group had group I (unilateral, $n=29$ ) and group III (bilateral, $n=17$ ). The control group had group II (unilateral, $\mathrm{n}=35$ ) and group IV (bilateral, $\mathrm{n}=16$ ).

Results: In group I, the drainage volume on the 1st and 2nd postoperative days and the total drainage decreased with statistical significance ( $<<0.05$ ). Between group III and group IV, group III had less drainage volume. In group III, the drainage volume on the 1st postoperative day and total drainage volume decreased statistically significantly $(\mathrm{p}<0.05)$. Between groups I and II, total blood loss showed no statistically significant difference, whereas between groups III and IV, the value was significantly different.

Conclusions: Intravenous administration of tranexamic acid with neutral drainage for 3 postoperative hours is a recommendable method because it can be helpful in reducing total blood loss in bilateral TKA.
\end{abstract}

Keywords: Knee, Arthroplasty, Blood loss, Transexamic acid, Neutral drainage

\section{Introduction}

Total knee arthroplasty (TKA) provides successful outcomes for degenerative knee arthritis patients; however, it has also been

Received October 16, 2015; Revised January 13, 2016;

Accepted February 15, 2016

Correspondence to: Dong Hwi Kim, MD

Department of Orthopaedic Surgery, Chosun University Hospital, 365

Pilmun-daero, Dong-gu, Gwangju 61453, Korea

Tel: +82-62-220-3147, Fax: +82-62-226-3379

E-mail: oskdh@chosun.ac.kr

Source of funding: This study was supported by research fund from

Chosun University Hospital, 2014.

This is an Open Access article distributed under the terms of the Creative Commons Attribution Non-Commercial License (http://creativecommons.org/licenses/by-nc/4.0/) which permits unrestricted non-commercial use, distribution, and reproduction in any medium, provided the original work is properly cited. associated with increased risk of massive blood loss that can sometimes be fatal. Blood transfusion for hemorrhage can cause various problems inherent in the blood transfusion process, including transfusion reactions, transmission of infections, and erroneous blood transfusion as well as increased infection rates after $\mathrm{TKA}^{1-3)}$. Several reports have demonstrated that intraoperative use of tranexamic acid can reduce blood loss after TKA ${ }^{4-7)}$, and the impact of drainage method on the volume of blood loss has been addressed in many studies ${ }^{8,9)}$. In this study, we attempted to evaluate the influence of tranexamic acid and drainage regimen on postoperative blood loss. We compared the patients who underwent intravenous injection of tranexamic acid (Shin Poong Pharm Co., Seoul, Korea) and neutral drainage for three postoperative hours (experimental group) and those with negative pressure drainage method immediately postoperatively without the 
use of tranexamic acid (control group).

\section{Materials and Methods}

Of the patients who underwent TKA for unilateral/bilateral osteoarthritis of the knee at our institution between March 2012 and January 2013, 97 TKA patients (64 unilateral and 33 bilateral) were included in this retrospective surgery. The exclusion criteria were $\geq 80$ years of age, a previous history of arterial occlusion such as myocardial infarction and cerebral infarction or of venous occlusion such as deep vein thrombosis (DVT), preoperative hemoglobin ( $\mathrm{Hb}$ ) level of $10 \mathrm{~g} / \mathrm{dL}$ or less, blood coagulation dysfunction, renal failure, a recent or previous seizure that precludes the use of tranexamic acid. In the experimental group, there were 46 TKA patients: 29 unilateral patients were classified into group I and 17 bilateral patients into group III. All the patients in the experimental group underwent intravenous injection of tranexamic acid during surgery and neutral drainage for three postoperative hours. The control group consisted of 51 patients: 35 unilateral patients were categorized into group II and the 16 bilateral patients into group IV. These patients underwent negative pressure drainage immediately postoperatively without the use of tranexamic acid.

The surgery was performed using the subvastus approach with a tourniquet pressure of $300 \mathrm{mmHg}$. An intramedullary guide was used for femoral and tibial alignment. The femoral intramedullary hole was filled with a piece of cortical bone obtained intraoperatively. Bone cement was used for fixation of the femur and tibia. In the experimental group, single intravenous injection of $10 \mathrm{mg} / \mathrm{kg}$ tranexamic acid was performed 30 minutes prior to the tourniquet was released following suture closure. For three postoperative hours, neutral drainage was maintained in groups I and III, and then negative pressure was applied. In groups II and IV, negative pressure drainage was utilized immediately postoperatively. In all four groups, drainage was removed based on the drainage volume assessed for two postoperative days.

For seven postoperative days, fondaparinux (Arixtra Injection; GlaxoSmithKline, Brentford, UK) was given for DVT prophylaxis. Postoperative development of DVT was examined by sonography among patients who presented with lower limb pain. Active straight leg raising exercises and knee exercises were initiated from the day of surgery and partial weight bearing was recommended. Blood transfusion was performed under the following conditions: if the $\mathrm{Hb}$ level was $8 \mathrm{mg} / \mathrm{dL}$, a $320 \mathrm{~mL}$ of packed red blood cell was transfused for a $\mathrm{Hb}$ of $1 \mathrm{mg} / \mathrm{dL}$ and even if the $\mathrm{Hb}$ level was $\geq 8 \mathrm{mg} / \mathrm{dL}$, transfusion was performed in the presence of anemic symptoms such as tachycardia. In all patients, body mass index (BMI), prothrombin time (PT), and activated partial thromboplastin time (aPTT) were assessed preoperatively. The $\mathrm{Hb}$ level and hematocrit were evaluated preoperatively and until the forth postoperative day. Postoperatively, the volume of blood loss was measured according to the methods of Nadler et al. ${ }^{10)}$ and Sehat et al. ${ }^{11)}$. In addition, the frequency and volume of blood transfusion were assessed.

Blood volume in man=height $\times 0.367+$ body weight $\times 0.032+0.604$

Blood volume in woman=height $\times 0.356+$ body weight $\times 0.033+0.183$

Change in blood volume $=$ patient's blood volume $\times$ (preoperative hematocrit [Hct]-postoperative $\mathrm{Hct}$ )/mean Hct

Blood loss=change in blood volume+volume transfused or retransfused

Fomula of total blood loss. Preoperative patient's blood volume was calcuated for women and men separately with use of the Nadler's fomula ${ }^{10)}$. Blood loss was calcuated with use of the Sehat's fomula ${ }^{11)}$.

Statistical analysis was performed using PASW ver. 21.0 (SPSS Inc., Chicago, IL, USA). T-test was used for comparison of groups with a level of statistical significance set at $\mathrm{p}<0.05$.

\section{Results}

There was no significant intergroup difference with regard to the preoperative BMI, PT, and aPTT (Table 1). The mean reduction in $\mathrm{Hb}$ level on the 4 th postoperative day was $3.34 \pm 1.65 \mathrm{~g} / \mathrm{dL}$ in group I, $3.60 \pm 1.07 \mathrm{~g} / \mathrm{dL}$ in group II, $3.91 \pm 1.20 \mathrm{~g} / \mathrm{dL}$ in group III, and $3.91 \pm 1.57 \mathrm{~g} / \mathrm{dL}$ in group IV. Although the reduction was significantly greater in group II than group I on the 1st postoperative day ( $\mathrm{p}=0.036)$, no statistically significant difference was noted in other comparisons (Tables 2 and 3 ).

The drainage volume assessed on the 1st postoperative day and 2 nd postoperative day was $339.1 \pm 171.4 \mathrm{~mL}$ and $117.5 \pm 92.9$ $\mathrm{mL}$, respectively, in group I and $494.0 \pm 198.3 \mathrm{~mL}$ and $186.0 \pm 72.0$ $\mathrm{mL}$, respectively, in group II. The combined total drainage volume until the 2nd postoperative day was significantly smaller in group I $(\mathrm{p}<0.05)$. The values were smaller in group III with $591.9 \pm 241.1 \mathrm{~mL}$ and $287.4 \pm 225.5 \mathrm{~mL}$, respectively, than group IV with $950.0 \pm 362.6 \mathrm{~mL}$ and $330.3 \pm 176.0 \mathrm{~mL}$, respectively. The differences between group III and group IV were statistically significant regarding the drainage volume assessed on the 1st postoperative and the total combined drainage volume until the 2nd postoperative day $(\mathrm{p}<0.05)$. The blood loss volume was not significantly different between group I and group II although the value was $12 \%$ smaller in group I $(1,147.9 \pm 485.5 \mathrm{~mL})$ than group 
Table 1. Demographic Data of the Patients

\begin{tabular}{|c|c|c|c|c|}
\hline Variable & Group I & Group II & Group III & Group IV \\
\hline No. of cases & 29 & 35 & 17 & 16 \\
\hline Age (yr), mean (range) & $72.2(64-84)$ & $69(55-82)$ & $66(56-71)$ & $67(54-80)$ \\
\hline $\operatorname{Sex}(M / F)$ & $3 / 19$ & $3 / 31$ & $0 / 11$ & $3 / 11$ \\
\hline $\operatorname{BMI}\left(\mathrm{kg} / \mathrm{m}^{2}\right)$ & 24.5 & 25.3 & 29.2 & 27.7 \\
\hline BP (systolic/diastolic) & $122 / 77$ & $122 / 75$ & $120 / 77$ & $118 / 74$ \\
\hline Preop Hb (g/dL) & 12.85 & 12.99 & 12.71 & 12.95 \\
\hline Preop Hct (\%) & 38.77 & 38.95 & 37.58 & 38.24 \\
\hline Preop PT (sec) & 10.0 & 10.5 & 10.11 & 10.46 \\
\hline Preop aPTT (sec) & 30.3 & 26.6 & 31.12 & 31.23 \\
\hline Preop blood volume (L) & 3.44 & 3.47 & 3.55 & 3.84 \\
\hline Transfusion rate (\%) & 10.3 & 17.1 & 5.9 & 43.8 \\
\hline
\end{tabular}

BMI: body mass index, BP: blood pressure, Preop: preoperative, Hb: hemoglobin, Hct: hematocrit, PT: prothrombin time, aPTT: activated partial thromboplastin time.

Table 2. Comparison between Two Unilateral Total Knee Arthoplasty Groups (Group I and Group II)

\begin{tabular}{lccc}
\hline \multicolumn{1}{c}{ Variable } & Group I & Group II & p-value \\
\hline Hb level (g/dL) & & & \\
Preoperative & $12.85 \pm 1.49$ & $12.99 \pm 0.95$ & 0.646 \\
POD 1 & $10.81 \pm 1.54$ & $11.57 \pm 1.27$ & 0.036 \\
POD 2 & $9.64 \pm 1.23$ & $9.60 \pm 1.21$ & 0.901 \\
POD 3 & $9.00 \pm 1.16$ & $8.90 \pm 0.95$ & 0.696 \\
POD 4 & $9.51 \pm 1.23$ & $9.39 \pm 0.85$ & 0.657 \\
Fall in Hb (g/dL) & $3.34 \pm 1.65$ & $3.60 \pm 1.07$ & \\
Amount of drain (mL) & & & \\
Day 1 & $339.1 \pm 171.4$ & $494.0 \pm 198.3$ & 0.002 \\
Day 2 & $117.5 \pm 92.9$ & $186.0 \pm 72.0$ & 0.002 \\
Total & $456.6 \pm 201.7$ & $680.1 \pm 213.5$ & 0.000 \\
Total blood loss (mL) & $1,147.9 \pm 485.5$ & $1,292.6 \pm 506.2$ & 0.251 \\
Transfusion (mL) & $55.2 \pm 172.5$ & $122.4 \pm 294.9$ & 0.285 \\
\hline
\end{tabular}

Values are presented as mean \pm standard deviation.

Hb: hemoglobin, POD: postoperative day.

II $(1,292.6 \pm 512.2 \mathrm{~mL})$. Between group III and group IV, the value was $35 \%$ smaller in group III than group IV $(1,329.0 \pm 377.0 \mathrm{~mL}$ vs. $2,043.2 \pm 1,143.3 \mathrm{~mL})$, indicating statistical significance $(\mathrm{p}=$ $0.029)$. The frequency of transfusion was lower in group I (10.3\%) than group II (17.1\%), but the difference was not statistically significant $(\mathrm{p}=0.436)$, whereas the value was significantly lower in group III (5.9\%) than group IV $(43.8 \%)(\mathrm{p}=0.011)$. The mean transfusion volume was less in group I $(55.2 \pm 172.5 \mathrm{~mL})$ than group II (122.4 $\pm 294.9 \mathrm{~mL})$, but the difference was not significant $(\mathrm{p}=0.285)$, whereas the value was significantly smaller in group
Table 3. Comparison between Two Bilateral Total Knee Arthroplasty Groups (Group III and Group IV)

\begin{tabular}{lrrr}
\hline \multicolumn{1}{c}{ Variable } & Group III & Group IV & p-value \\
\hline Hb level (g/dL) & & & \\
Preoperative & $12.71 \pm 1.01$ & $12.95 \pm 1.42$ & 0.572 \\
POD 1 & $9.98 \pm 1.70$ & $10.45 \pm 1.95$ & 0.475 \\
POD 2 & $9.20 \pm 1.07$ & $9.00 \pm 1.36$ & 0.644 \\
POD 3 & $8.12 \pm 0.91$ & $8.28 \pm 0.89$ & 0.620 \\
POD 4 & $8.80 \pm 0.92$ & $9.04 \pm 0.87$ & 0.443 \\
Fall in Hb (g/dL) & $3.91 \pm 1.20$ & $3.91 \pm 1.57$ & \\
Amount of drain (mL) & & & \\
Day 1 & $591.9 \pm 241.1$ & $950.0 \pm 362.6$ & 0.002 \\
Day 2 & $287.4 \pm 225.5$ & $330.3 \pm 176.0$ & 0.549 \\
Total & $879.3 \pm 369.0$ & $1,280.3 \pm 424.0$ & 0.007 \\
Total blood loss (mL) & $1,329.0 \pm 377.0$ & $2,043.2 \pm 1,143.3$ & 0.029 \\
Transfusion (mL) & $37.6 \pm 155.2$ & $480.0 \pm 650.5$ & 0.017 \\
\hline
\end{tabular}

Values are presented as mean \pm standard deviation.

Hb: hemoglobin, POD: postoperative day.

III $(37.6 \pm 155.2 \mathrm{~mL})$ than group IV $(480.0 \pm 650.5 \mathrm{~mL})(\mathrm{p}=0.017)$ (Tables 2 and 3 ).

\section{Discussion}

Knees surgeons have increased efforts to reduce complications associated with massive blood loss after TKA. Among various methods, tranexamic acid injection and drainage are most preferred and recent reports have documented successful outcomes of the method. In this study, we retrospectively investigated the 
influence of the combined use of tranexamic acid and drainage on blood loss: among bilateral TKA patients, the method resulted in statistically significantly less drainage volume, transfusion frequency, transfusion volume, and blood loss.

TKA offers satisfying treatment results, but it has been associated with massive blood loss compared to other orthopedic operations. Lotke et al. ${ }^{12)}$ reported a mean blood loss of $1,518 \mathrm{~mL}$ in their TKA patients, indicating the increased necessity of blood transfusion after TKA. Resection of the bone or soft tissue during TKA can result in blood loss from the cut surface. Besides such 'visible' blood loss, hidden blood loss due to bleeding into the soft tissue, despite not negligible in terms of the amount, can cause underestimation of the total amount of blood loss. Sehat et al. ${ }^{11,13)}$ calculated the amount of blood loss using Hct. In their study, the mean postoperative blood loss was 1,498 $\mathrm{mL}$, and approximately $735 \mathrm{~mL}$ (49\%) of which was hidden blood loss. In our study, in order to assess the exact amount of blood loss, we calculated the preoperative total blood volume according to the patient's height, weight, and gender using the Nadler's formula ${ }^{10)}$ and measured the amount of blood loss according to the change in Hct between the preoperative and postoperative assessments as suggested by Sehat et al. ${ }^{11)}$.

Blood transfusion can be required after TKA. Studies have reported the frequency of transfusion after unilateral TKA as 4\%$46 \%$ and that after bilateral TKA as $31 \%-72 \%{ }^{14-18)}$. Allogeneic blood transfusion is the most common form of transfusion performed after TKA. However, it carries inherent risks such as transmission of infectious diseases. Dodd ${ }^{19)}$ documented the risk of human immunodeficiency virus transmission as $1 / 225,000$ per unit of transfusion, hepatitis B virus transmission as $1 / 200,000$, hepatitis $C$ virus transmission as $1 / 30,000-1 / 150,000$, and human T-cell lymphotropic virus transmission as $1 / 50,000$. In addition, some studies have reported that allogeneic transfusion increases the risk of postoperative infection compared to autologous transfusion or no use of transfusion. In a study by Rosencher et al. ${ }^{3)}$, postoperative infection rate was lower in the autologous transfusion group than the allogeneic transfusion group (1\% vs. $4 \%$ ) in patients with knee and hip arthroplasty. Friedman et al. $^{2)}$ compared the infection rates between the allogeneic transfusion group and the no transfusion/autologous transfusion group following total hip arthroplasty or TKA: the rate of upper/ lower respiratory tract infection and the rate of wound inflammation/infection at the surgical site were significantly higher in the former group $(2.1 \%$ and $2.4 \%$, respectively) than the latter group (1.7\% and $1.7 \%$, respectively). Hart et al. ${ }^{20)}$ found that the incidence of mortality significantly increased in patients with al- logeneic transfusion than those without blood transfusion after unilateral TKA. Newman et al. ${ }^{21)}$ reported that the rate of revision due to suspicion of infection within 3 postoperative months was significantly higher in patients with allogeneic transfusion (1.67\%) than those with autologous transfusion $(0.66 \%)$ or without transfusion $(0.75 \%)$. Such complications of allogeneic transfusion have recently prompted many surgeons to attempt other techniques to reduce blood loss in TKA patients.

In particular, tranexamic acid administration is widely accepted by surgeons as a strategy for blood loss reduction. Tranexamic acid is a synthetic antifibrinolytic agent that reversibly binds to lysine union sites of the plasmin and plasminogen ${ }^{22)}$. One of the reported adverse effects of tranexamic acid is blood clot formation that can lead to DVT, pulmonary embolism, and cerebral infarction; however, the incidences of such side effects were not statistically significantly high in many studies ${ }^{5,23,24)}$. In the current study, complications such as DVT were not found to have developed in sonography among patients who received tranexamic acid and complained lower limb pain. Tranexamic acid can be administered intravenously, intra-articularly, or orally. The optimal administration method and dosage and efficacy of tranexamic acid have yet to be established. Maniar et al. ${ }^{5)}$ compared groups that underwent intravenous injection of tranexamic acid preoperatively, intraoperatively, and 1-3 times postoperatively and the group that received a single local injection. Their finding was that blood loss/drainage volume could be significantly reduced by more than 2 injections or a local injection. Charoencholvanich and Siriwattanasakul ${ }^{4)}$ reported that intravenous injection before surgery, 10 minutes before tourniquet deflation, and three hours after surgery combined with 5 days of oral administration was remarkably effective in decreasing postoperative drainage volume, $\mathrm{Hb}$ level, frequency of transfusion, and transfused volume without any side effects. Tanaka et al. ${ }^{7)}$ reported that 1-2 times of intravenous injection of tranexamic acid before surgery and on tourniquet deflation resulted in significant reduction in blood loss and transfusion volume without the risk of complications compared to the group without the use of tranexamic acid. In a study by Orpen et al. ${ }^{6}$, one intravenous injection of tranexamic acid given 10 minutes prior to tourniquet deflation was effective in reducing blood loss in the early postoperative period. Benoni et al. ${ }^{25)}$ reported that the maximum blood concentration was achieved within 5-15 minutes after intravenous injection of tranexamic acid. In the current study, we performed one intravenous injection of $10 \mathrm{mg} / \mathrm{kg}$ tranexamic acid 30 minutes before tourniquet release during suture closure after implant insertion.

Temporary clamping of drain is another method reported to 
be effective in reducing blood loss and transfusion volume after TKA. Pornrattanamaneewong et al. ${ }^{9)}$ reported that compared to the group where tranexamic acid was given intravenously and orally during and after surgery, the amount of blood loss, blood transfusion, and $\mathrm{Hb}$ level reduction were significantly smaller the group where the drain was clamped for three postoperative hours, unclamped for another 3 hours, and then reclamped for the next three hours. Aksoy et al. ${ }^{8)}$ found that two-hour postoperative drain clamping without intraoperative bleeding control resulted in no significant difference with intraoperative bleeding control without clamping. Therefore, they concluded that twohour drain clamping could be as effective as intraoperative bleeding control in terms of blood loss reduction, thereby shortening the operation time. In the current study, intraoperative administration of tranexamic acid combined with 3-hour postoperative neutral drainage resulted in a significant decrease in the volume of drainage in the unilateral and bilateral TKA patients in the experimental group than those in the control group. In addition, the amount of blood loss, transfusion frequency, and transfusion volume were remarkably smaller in the experimental group; the difference was at a statistically significantly level especially for the bilateral TKA patients in the experimental group.

In this study, we observed that the experimental group that underwent intraoperative injection of tranexamic acid and neutral drainage for three hours after TKA had significantly less drainage volume, leading us to believe that the method could be helpful in reducing unexpected blood loss after surgery. On the other hand, there was no notable difference with the control group with regard to the $\mathrm{Hb}$ level reduction, amount of blood loss, and transfusion frequency and volume. In addition, the experimental group showed greater $\mathrm{Hb}$ level reduction on the 1st postoperative

A

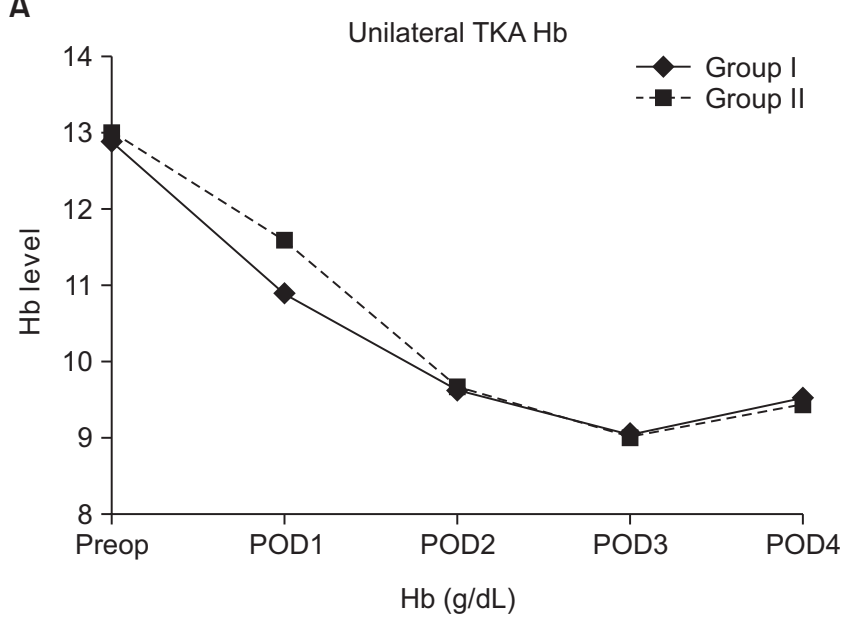

day. We attribute this to the higher transfusion rate in the control group than the experimental group (17\% vs. $10 \%)$ on the 1 st and 2nd postoperative days. In particular, bilateral TKA patients in the experimental group exhibited significantly better results than those in the control group with regard to the drainage volume, blood loss volume, and transfusion frequency and volume. Taking all these findings into account, we believe that the intraoperative injection of tranexamic acid and three postoperative hour neutral drainage method would prevent acute massive blood loss and reduce symptoms related to blood loos, thereby decreasing the frequency and volume of transfusion. Regardless of the group, there was a tendency for the $\mathrm{Hb}$ level to fall drastically on the 1st and 2nd postoperative days, decrease less markedly on the 3rd postoperative day, and then rather increase on the 4th postoperative day. Therefore, we suggest that blood transfusion should not be determined based only on the $\mathrm{Hb}$ level to avoid unnecessary transfusion, which should be investigated more thoroughly in further studies (Fig. 1). The limitations of this study include the use of two variables (tranexamic acid and neutral drainage for three postoperative hours) and the small sample size. We think that univariate analyses using a single variable should be performed in future studies of a prospective design involving a larger study population. Furthermore, the optimal dosage of tranexamic acid should also investigated in future research.

\section{Conclusions}

Administration of tranexamic acid 30 minutes prior to tourniquet deflation combined with application of neutral drainage for three postoperative hours was effective in reducing blood loss and preventing side effects of transfusion. The method would be

B

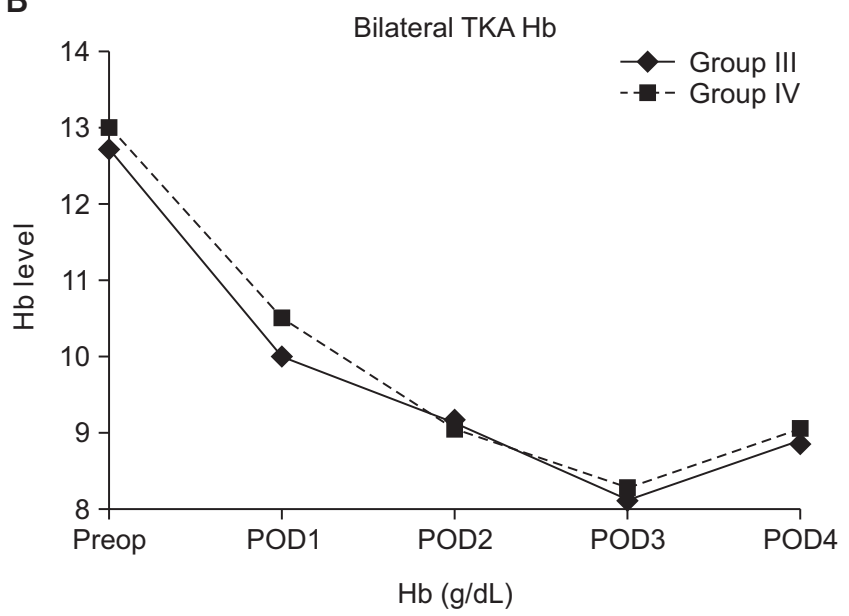

Fig. 1. Hemoglobin ( $\mathrm{Hb}$ ) concentration level in unilateral total knee arthroplasty (TKA) (A) and bilateral TKA (B). POD: postoperative day. 
helpful in decreasing the frequency and volume of transfusion and the amount of blood loss in TKA, especially in bilateral cases.

\section{Conflict of Interest}

No potential conflict of interest relevant to this article was reported.

\section{References}

1. Bong MR, Patel V, Chang E, Issack PS, Hebert R, Di Cesare PE. Risks associated with blood transfusion after total knee arthroplasty. J Arthroplasty. 2004;19:281-7.

2. Friedman R, Homering M, Holberg G, Berkowitz SD. Allogeneic blood transfusions and postoperative infections after total hip or knee arthroplasty. J Bone Joint Surg Am. 2014; 96:272-8.

3. Rosencher N, Kerkkamp HE, Macheras G, Munuera LM, Menichella G, Barton DM, Cremers S, Abraham IL; OSTHEO Investigation. Orthopedic Surgery Transfusion Hemoglobin European Overview (OSTHEO) study: blood management in elective knee and hip arthroplasty in Europe. Transfusion. 2003;43:459-69.

4. Charoencholvanich K, Siriwattanasakul P. Tranexamic acid reduces blood loss and blood transfusion after TKA: a prospective randomized controlled trial. Clin Orthop Relat Res. 2011;469:2874-80.

5. Maniar RN, Kumar G, Singhi T, Nayak RM, Maniar PR. Most effective regimen of tranexamic acid in knee arthroplasty: a prospective randomized controlled study in 240 patients. Clin Orthop Relat Res. 2012;470:2605-12.

6. Orpen NM, Little C, Walker G, Crawfurd EJ. Tranexamic acid reduces early post-operative blood loss after total knee arthroplasty: a prospective randomised controlled trial of 29 patients. Knee. 2006;13:106-10.

7. Tanaka N, Sakahashi H, Sato E, Hirose K, Ishima T, Ishii S. Timing of the administration of tranexamic acid for maximum reduction in blood loss in arthroplasty of the knee. J Bone Joint Surg Br. 2001;83:702-5.

8. Aksoy Y, Altinel L, Kose KC. The comparison of the effects of intraoperative bleeding control and postoperative drain clamping methods on the postoperative blood loss and the need for transfusion following total knee arthroplasty. Acta Orthop Traumatol Turc. 2011;45:190-4.

9. Pornrattanamaneewong C, Narkbunnam R, Siriwattanasakul P, Chareancholvanich K. Three-hour interval drain clamping reduces postoperative bleeding in total knee arthroplasty: a prospective randomized controlled trial. Arch Orthop Trauma Surg. 2012;132:1059-63.

10. Nadler SB, Hidalgo JH, Bloch T. Prediction of blood volume in normal human adults. Surgery. 1962;51:224-32.

11. Sehat KR, Evans RL, Newman JH. Hidden blood loss following hip and knee arthroplasty. Correct management of blood loss should take hidden loss into account. J Bone Joint Surg Br. 2004;86:561-5.

12. Lotke PA, Faralli VJ, Orenstein EM, Ecker ML. Blood loss after total knee replacement. Effects of tourniquet release and continuous passive motion. J Bone Joint Surg Am. 1991;73: 1037-40.

13. Sehat KR, Evans R, Newman JH. How much blood is really lost in total knee arthroplasty? Correct blood loss management should take hidden loss into account. Knee. 2000;7: 151-5.

14. Bierbaum BE, Callaghan JJ, Galante JO, Rubash HE, Tooms RE, Welch RB. An analysis of blood management in patients having a total hip or knee arthroplasty. J Bone Joint Surg Am. 1999;81:2-10.

15. Keating EM, Meding JB, Faris PM, Ritter MA. Predictors of transfusion risk in elective knee surgery. Clin Orthop Relat Res. 1998;(357):50-9.

16. Larocque BJ, Gilbert K, Brien WF. A point score system for predicting the likelihood of blood transfusion after hip or knee arthroplasty. Transfusion. 1997;37:463-7.

17. Salido JA, Marín LA, Gomez LA, Zorrilla P, Martinez C. Preoperative hemoglobin levels and the need for transfusion after prosthetic hip and knee surgery: analysis of predictive factors. J Bone Joint Surg Am. 2002;84:216-20.

18. Surgenor DM, Wallace EL, Churchill WH, Hao SH, Chapman RH, Poss R. Red cell transfusions in total knee and total hip replacement surgery. Transfusion. 1991;31:531-7.

19. Dodd RY. The risk of transfusion-transmitted infection. $\mathrm{N}$ Engl J Med. 1992;327:419-21.

20. Hart A, Khalil JA, Carli A, Huk O, Zukor D, Antoniou J. Blood transfusion in primary total hip and knee arthroplasty. Incidence, risk factors, and thirty-day complication rates. J Bone Joint Surg Am. 2014;96:1945-51.

21. Newman ET, Watters TS, Lewis JS, Jennings JM, Wellman SS, Attarian DE, Grant SA, Green CL, Vail TP, Bolognesi MP. Impact of perioperative allogeneic and autologous blood transfusion on acute wound infection following total knee and total hip arthroplasty. J Bone Joint Surg Am. 2014;96: 279-84. 
22. Shapiro F, Zurakowski D, Sethna NF. Tranexamic acid diminishes intraoperative blood loss and transfusion in spinal fusions for duchenne muscular dystrophy scoliosis. Spine (Phila Pa 1976). 2007;32:2278-83.

23. Alshryda S, Sarda P, Sukeik M, Nargol A, Blenkinsopp J, Mason JM. Tranexamic acid in total knee replacement: a systematic review and meta-analysis. J Bone Joint Surg Br. 2011;93:1577-85.

24. Gomez-Barrena E, Ortega-Andreu M, Padilla-Eguiluz NG,
Perez-Chrzanowska H, Figueredo-Zalve R. Topical intraarticular compared with intravenous tranexamic acid to reduce blood loss in primary total knee replacement: a doubleblind, randomized, controlled, noninferiority clinical trial. J Bone Joint Surg Am. 2014;96:1937-44.

25. Benoni G, Bjorkman S, Fredin H. Application of pharmacokinetic data from healthy volunteers for the prediction of plasma concentrations of tranexamic acid in surgical patients. Clin Drug Investig. 1995;10:280-7. 